\title{
First Principles Modeling and Simulation of Zr-Si-B-C-N ceramics: Developing Hard and OxidationResistant Coatings
}

\author{
Atreyi Dasmahapatra ${ }^{1}$, Efstathios Meletis ${ }^{2}$, and Peter Kroll ${ }^{1, *}$, \\ ${ }^{1}$ Department of Chemistry and Biochemistry, The University of Texas at Arlington, \\ 700 Planetarium Place, Arlington, Texas 76019, United States. \\ ${ }^{2}$ Department of Materials Science and Engineering, University of Texas at Arlington, 501 \\ West First St., Arlington, Texas 76019, United States.
}

\begin{abstract}
:
We model amorphous ZrSiBCN ceramics combining ab-initio molecular dynamic simulations with melt-quench and simulated annealing techniques. Starting from the parent composition $\mathrm{Zr}_{42} \mathrm{~B}_{32} \mathrm{C}_{8} \mathrm{~N}_{18}$ we systematically increase the $\mathrm{Si}_{3} \mathrm{~N}_{4}$ content along four different pathways in the composition diagram and evaluate trends in structure and properties. Mixtures of $\mathrm{ZrB}_{2}, \mathrm{ZrN}$, and $\mathrm{ZrC}$ exhibit $\mathrm{Zr}$ layers as well as $\mathrm{ZrB}_{2}$ and $\mathrm{ZrN}(\mathrm{C})$ nuclei, but addition of $\mathrm{Si}_{3} \mathrm{~N}_{4}$ reduces structural order in the models. Elastic moduli decrease with increasing $\mathrm{Si}_{3} \mathrm{~N}_{4}$ content to values less thanexpected of a simple mixture model. Thus, while addition of $\mathrm{Si}_{3} \mathrm{~N}_{4}$ to amorphous $\mathrm{ZrBCN}$ coatings may improve oxidation resistance, this needs to be balanced with desired mechanical properties.
\end{abstract}

Keywords:

Hard coatings, density functional theory calculations, ab-initio molecular dynamics, elastic moduli, nucleation 


\section{Introduction:}

Zirconium borides, carbides andnitrides are ultra high temperature ceramics (UHTCs) with melting points above $3000^{\circ} \mathrm{C}$. [1, 2]Theyare frequently used as protective coatings due to their refractory nature and high hardness.[3, 4]Thin films of $\mathrm{ZrB}_{2}$, $\mathrm{ZrC}$, or $\mathrm{ZrN}$ are synthesized viaphysical vapor deposition (PVD) processes, for instance byreactive magnetron sputtering[5]or viachemical vapor deposition (CVD) techniques.[6, 7]In a recent study, quaternary ZrBCN films with thickness between 3.5 and $4.1 \mu \mathrm{m}$ have been synthesized by pulsed magnetron sputtering of $\mathrm{Zr}$ and $\mathrm{B}_{4} \mathrm{C}$ targets in flowing $\mathrm{N}_{2}$. [8, 9]Thesecoatings exhibit hardness up to36 GPa, and the high value is attributed toa nanodomain structureof ZrN grainsjoined via monolayer interfaces.[8, 9]

At elevated temperatureszirconium-basedUHTC’shave pooroxidation resistance, unfortunately. [10] $\mathrm{ZrB}_{2}$ forms $\mathrm{ZrO}_{2}$ and $\mathrm{B}_{2} \mathrm{O}_{3}$ upon oxidation, and although a protective layer of glassy $\mathrm{B}_{2} \mathrm{O}_{3}$ forms, it evaporates rapidly at temperatures exceeding $1200^{\circ} \mathrm{C}$ exposing a non-protective $\mathrm{ZrO}_{2}$ layer.[11-13] Zirconium carbides oxidizeat temperatures lower than $\mathrm{ZrB}_{2}$, at $1000^{\circ} \mathrm{C}$.[14]Zirconium nitrides have the leastoxidation resistance forming $\mathrm{ZrO}_{2}$ at temperatures as low as $500^{\circ} \mathrm{C}$.[15-17]The quaternary $\mathrm{ZrBCN}$ films mentioned above show strong oxidation at $800^{\circ} \mathrm{C}$. [8, 9]

An approachto improveoxidation resistance of zirconium boridesat high temperatures is the addition ofa silicon bearing compound, for example silicon nitride[18]or siliconcarbide. [19]Significant improvements to oxidation resistance (upto $1900^{\circ} \mathrm{C}$ ) have been reported for $\mathrm{ZrB}_{2}$ and $20 \mathrm{vol} \%$ SiC composites.[20][21][22]Oxidation resistance of $\mathrm{ZrB}_{2}-\mathrm{Si}_{3} \mathrm{~N}_{4}$ ceramics wasfound to increaseto 1300-1400 ${ }^{\circ} \mathrm{C}$ with increasing $\mathrm{Si}_{3} \mathrm{~N}_{4}$ contentdue to formation of a protective layer of borosilicate glass. Addition of $10 \mathrm{~mol} \%$ of $\mathrm{Cr}$ and Ta diborides to these $\mathrm{ZrB}_{2}-\mathrm{Si}_{3} \mathrm{~N}_{4}$ coatings improved the oxidation resistance further.[23] 
The high temperature mechanical properties of these materials have also been another prominent field of study. Addition of 20 vol\% SiC to $\mathrm{ZrB}_{2}$ decreases the Young's modulus of $510 \mathrm{GPa}$ at room temperature to $420 \mathrm{GPa}$ at $1400^{\circ} \mathrm{C}$.[24]At $1600^{\circ} \mathrm{C}$, the Young's modulus thenplunges to 100 GPa.Another study finds the Young's modulus of $\mathrm{ZrB}_{2}$-SiC composites dropping to $210 \mathrm{GPa}$ at $1500^{\circ} \mathrm{C}$ compared to $510 \mathrm{GPa}$ at room temperature.[25]This decrease in Young's modulus is attributed to the presence of oxides at grain boundaries in the polycrystalline material. [26]The presence of $5 \% \mathrm{Si}_{3} \mathrm{~N}_{4}$ as a sintering aid in pure $\mathrm{ZrB}_{2}$ also lowers the Young’s Modulus to $419 \mathrm{GPa}$.[27] At room temperature, $\mathrm{ZrB}_{2}$-SiC composites have exhibited Vickers hardness of 17-24 GPa depending on the SiC particle size.[28, 29]Addition of $\mathrm{Si}_{3} \mathrm{~N}_{4}$ to $\mathrm{ZrB}_{2}$ and $\mathrm{SiC}\left(\mathrm{ZrB}_{2}+20\right.$ $\mathrm{SiC}+4 \mathrm{Si}_{3} \mathrm{~N}_{4}$ ), decreases hardness to $14 \mathrm{GPa}$.[27]

In this work, we will investigate the impact of $\mathrm{Si}_{3} \mathrm{~N}_{4}$ addition on structure and properties of ZrSiBCN materials using structure modeling and ab-initio calculations. Previously, Houska et al. used computational methods toinvestigateatomic and electronic structure of ZrBCN.[30]They compared different compositions and characterized covalent and metallic bonding in these materials. They used rock-salt type $\mathrm{Zr}(\mathrm{N}+\mathrm{C}+\mathrm{B})$ solid-solutionsas models to rationalize the high hardness observed in $\mathrm{ZrBCN}$ films.The same group also studied some MSiBCN ( $\mathrm{M}=\mathrm{Ti}$, Hf and $\mathrm{Zr}$ ) films and investigatedthe impact of the metal $\mathrm{M}$ on segregation and oxidation resistance.[31]

Our exploration startswiththe composition $\mathrm{Zr}_{42} \mathrm{~B}_{32} \mathrm{C}_{8} \mathrm{~N}_{18}$, a ternary mixture of $\mathrm{ZrN}$, $\mathrm{ZrB}_{2}$, and $\mathrm{ZrC}$. This composition is close to the composition $\mathrm{Zr}_{41} \mathrm{~B}_{30} \mathrm{C}_{8} \mathrm{~N}_{19}$ of sputtered films, for which a hardness of $36 \mathrm{GPa}$ has been measured.[8, 9]Varying the ZrN, ZrB 2 , and $\mathrm{Si}_{3} \mathrm{~N}_{4}$ phase content, we generate structure models via melt-quench and subsequent annealing techniques. We will show that formation of nm-sized $\mathrm{ZrN}$ and $\mathrm{ZrB}_{2}$ nuclei happenseven at the short time-scales of our computer simulation. We compute elastic moduli and Vickers hardnessand highlightthe impact of $\mathrm{Si}_{3} \mathrm{~N}_{4}$ addition to $\mathrm{ZrSiBCN}$ materials. 


\section{Computational details:}

Structures and energies of ZrSiBCN models and of crystalline reference phasesare computed within density functional theory (DFT). [32-36]We use the Generalized Gradient Approximation (GGA)[37], [38]forelectron exchange and correlation together with theProjector Augmented Wave (PAW) method.[39, 40]For optimizations and property calculations we use a cut-off of $350 \mathrm{eV}$ for the expansion of the wave function into a plane wave basis set. Sampling of the Brillouin zone isdoneat the $\Gamma$-point for amorphous models and using appropriate meshes for all crystalline models.

We create structures of amorphous ZrSiBCN by a "melt-quench" approach, which is followed - for selected models - by a sequence of simulated annealing. For bothmeltquench and the simulated annealing processes, we perform ab-initio molecular dynamic (aiMD) simulations under a canonical(NVT) ensemble. We use a time-step of 2 fs for integrating the equations of motion and controltemperature via velocity rescaling. The velocity rescaling is performed at every time-step. To save computational costs, we reduce the cutoff energy to $205 \mathrm{eV}$ during aiMD simulations.In the beginning of themeltquenchprocedure, we place100 atoms randomly into a box with a volume approximately reflecting a mixture of the constituting phases $\mathrm{ZrB}_{2}, \mathrm{ZrN}, \mathrm{ZrC}$, and $\mathrm{Si}_{3} \mathrm{~N}_{4}$.For example, models with composition $\mathrm{Zr}_{42} \mathrm{~B}_{32} \mathrm{C}_{8} \mathrm{~N}_{18}$ are initially set to a density of $6.0 \mathrm{~g} / \mathrm{cm}^{3}$, and adding $\mathrm{Si}_{3} \mathrm{~N}_{4}$ lowers the density accordingly. Then we create a "liquid" state via simulation at $5000 \mathrm{~K}$ for $10 \mathrm{ps}$ (5,000 time-steps) during which the system loses all memory of its initial configuration. Thisrandomization is supported by the fact that atoms exchange more than $90 \%$ of their nearest neighbors duringthis period.

Subsequently,theensemble is cooled to $3000 \mathrm{~K}$ within $20 \mathrm{ps}$, which corresponds to a cooling rate of $10^{14} \mathrm{Ks}^{-1}$. At $3000 \mathrm{~K}$, the system is again equilibrated for $20 \mathrm{ps}$, after which it is cooled to $2000 \mathrm{~K}$ within $20 \mathrm{ps}$ (cooling rate of $5 \cdot 10^{13} \mathrm{Ks}^{-1}$ ) and finally down to $300 \mathrm{~K}$ in $20 \mathrm{ps}$ (cooling rate of $8.5 \cdot 10^{13} \mathrm{Ks}^{-1}$ ). The overall simulation time to generate a 
“melt-quench” structure in this study is almost two orders of magnitude (about 50 times) longer than in Ref. [30]. The time-temperaturesequence of the melt-quench process is displayed in Figure 1 (left).For each composition, we generate five independent models via the melt-quench procedure (total 65 models). All structures obtained after the meltquench procedureare finally optimized (positions and cell parameters) by converging forces to 5 meV/Åand stresses below 1 kBar.Final volumes of optimized models are within 3\% of their initial volume.

Simulated annealing startsafteroptimization ofmelt-quench models. For every composition, we choose the melt-quench model with lowest energy and simulate this at $800 \mathrm{~K}$ for 2 ps (total 13 models).Then we sequentially heatthemodelto 1200, 1800, 2200, 2600, 3000, and $3400 \mathrm{~K}$ using a heating rate of $2.5 \times 10^{14} \mathrm{Ks}^{-1}$, while keeping the temperature constant for 5 to 20 psonce the desired temperature has been achieved.A graphwith the temperatureprofile duringsimulated annealing is shown in Figure 1 (right).During the annealing procedure, we take a snapshot ofthe model every 2 ps and optimize the structure, while the annealing simulation continues. The optimized configurationstrack the underlying potential energy surface, above which the structure evolves at elevated temperatures. Moreover, since the annealing procedure effectively “heals” structural defects, we receivea sequence of models of which some have energies lower than the initial configurations. After a first complete annealing simulation, we choose the lowest energy model once again and repeat the annealing procedure all over.This is illustrated in Figure 2 for the model of $Z_{27} \mathrm{Si}_{15} \mathrm{~B}_{22} \mathrm{C}_{8} \mathrm{~N}_{28}$. The figure on the left illustrates the first annealing process. The red dot shows the energy of the initial structure of this model of $\mathrm{Zr}_{27} \mathrm{Si}_{15} \mathrm{~B}_{22} \mathrm{C}_{8} \mathrm{~N}_{28}$ as received after optimization of the melt quench model. Some healing of structural imperfections occurs during annealing at $1800 \mathrm{~K}$, and a new“lowest energy structure” for the model is found. Further annealing during this run does not produce a lower energy structure, so the model is taken and, once again, subjected to a second annealing procedure.During the second annealing procedure, for 
which longer "holding” times have been chosen (see Fig. 2 (right)), another drop in energy is observed. A third annealingprocess (not shown here) did not produce a model with even lower energy. In general, we consider a model being "converged” with respect to energy gains, if the maximum gain within annealing was less than $1 \mathrm{eV}$ for 100 atoms (0.01 eV/atom).

We compute elastic constants $\mathrm{c}_{\mathrm{ij}}$ via the strain-stress relationship given by Hooke’s Law for all models, those received after the melt-quench procedure (5 for each composition) and for models with lowest energy obtained from the annealing procedure (1 for each composition). Details of the computational procedurehave beengivenin Ref.[41].Weestimate Bulk modulus (B), Young's modulus (E), and shear modulus (G)as well asPoisson's ratio for each structure within the approximations of Voigt, Reuss and Hill.[42-44]We evaluate Vickers Hardness, $\mathrm{H}_{\mathrm{V}}$, usingits empirical relation to $\mathrm{B}$ and $\mathrm{G}$ as proposed by Chen et al..[45]

\section{Results:}

\section{a) Composition Diagram}

We investigateZrSiBCNstructures with composition located in the quaternaryZrB $\mathrm{rB}_{2} \mathrm{ZrN}$ $\mathrm{ZrC}-\mathrm{Si}_{3} \mathrm{~N}_{4}$ phase diagram. Every model comprises of 100 atoms. We compute mole coefficient and mole fraction (mol\%) directly from composition, e.g. $\mathrm{Zr}_{25} \mathrm{Si}_{18} \mathrm{~B}_{16} \mathrm{C}_{8} \mathrm{~N}_{33}==$ $8 \cdot \mathrm{ZrC}+9 \cdot \mathrm{ZrN}+8 \cdot \mathrm{ZrB}_{2}+6 \cdot \mathrm{Si}_{3} \mathrm{~N}_{4}==25.8 \mathrm{~mol} \% \mathrm{ZrC}+29.0 \mathrm{~mol} \% \mathrm{ZrN}+25.8 \mathrm{~mol} \%$ $\mathrm{ZrB}_{2}+19.4 \mathrm{~mol} \% \mathrm{Si}_{3} \mathrm{~N}_{4}$. We fix the amount of $\mathrm{ZrC}$ in all models(8 formula units of $\mathrm{ZrC}$ ) and represent the composition of the remaining $\mathrm{ZrB}_{2}-\mathrm{ZrN}-\mathrm{Si}_{3} \mathrm{~N}_{4}$ contentin a ternary diagram (Figure 3).We acknowledge that this is not a perfect slice of the quaternary phase diagram, since the mol\% of $\mathrm{ZrC}$ in the $\mathrm{ZrSiBCN}$ structures varies depending on the content of the other constituents. The small amount of ZrC is very helpful for structure 
simulations, because C may substitute for both $\mathrm{N}$ (in ZrN-like arrangements) and B (in $\mathrm{ZrB}_{2}$-like fragments).

Startingfrom the "parent" composition of $\mathrm{Zr}_{42} \mathrm{~B}_{32} \mathrm{C}_{8} \mathrm{~N}_{18}\left(\mathrm{Zr}_{42} \mathrm{~B}_{32} \mathrm{C}_{8} \mathrm{~N}_{18}==8 \cdot \mathrm{ZrC}+\right.$ $18 \cdot \mathrm{ZrN}+16 \cdot \mathrm{ZrB}_{2}$ ), which is close to the experimentally realized composition of $\mathrm{Zr}_{41} \mathrm{~B}_{30} \mathrm{C}_{8} \mathrm{~N}_{19}$ - we adopt four different pathways (1)-(4) to incorporate $\mathrm{Si}_{3} \mathrm{~N}_{4}$. These paths are indicated in the ternary composition diagram shown in Figure 3. Along each pathway we add units of $\mathrm{Si}_{3} \mathrm{~N}_{4}$ to the model, while balancingthe total number of atoms in a model (100) by changingthe amount of $\mathrm{ZrB}_{2}$ and $\mathrm{ZrN}$. The net change along the four pathways is (1) $+\mathrm{Si}_{3} \mathrm{~N}_{4}-\mathrm{ZrB}_{2}-2 \mathrm{ZrN},(2)+6 \mathrm{Si}_{3} \mathrm{~N}_{4}-8 \mathrm{ZrB}_{2}-9 \mathrm{ZrN}$, (3) $+2 \mathrm{Si}_{3} \mathrm{~N}_{4}-4 \mathrm{ZrB}_{2}-\mathrm{ZrN}$, and (4) $+\mathrm{Si}_{3} \mathrm{~N}_{4}-3 \mathrm{ZrB}_{2}+\mathrm{ZrN}$.Path (1) is almost parallel to the $\mathrm{ZrN}_{-} \mathrm{Si}_{3} \mathrm{~N}_{4}$ tie-line, while path (3) is approximately parallel to the $\mathrm{ZrB}_{2}-\mathrm{Si}_{3} \mathrm{~N}_{4}$ tie-line.

We generate five independent models for each compositionvia the melt-quench procedure, and subject the lowest-energy model of each composition to the simulatedannealing procedure.From the annealing procedure we receive one more model for each composition. Hence, in total we analyze six models for each of the 13 compositions. For reference, we compute crystalline structures of $\mathrm{ZrB}_{2}$, $\mathrm{ZrC}$ and $\mathrm{ZrN}$ (both $\mathrm{NaCl}-$ type), $\beta-\mathrm{Si}_{3} \mathrm{~N}_{4}, \mathrm{~h}-\mathrm{BN}$ and c-BN.

\section{b) Structure and Ordering:}

Figure 4 shows four representative structuresfrom each of the four pathways as obtained after two cycles of simulated annealing. It is difficult to provide simple quantitative measures for bonding in these mixed systems. However, we find average bond distances comparable with those computed for crystal structures. For instance,Zr-B $(2.42 \AA$ in the

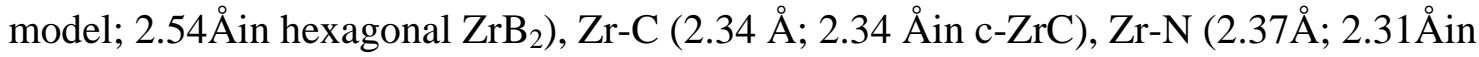

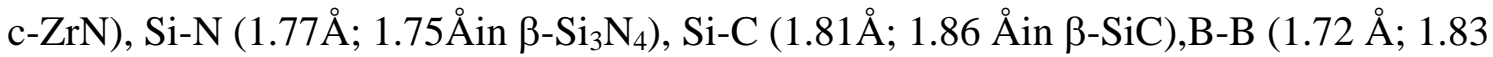

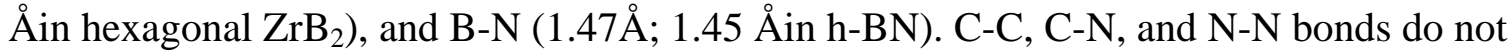


appear in these models.We also find occasionallysome Zr-Si bonds(2.79 $\AA$; $2.72 \AA$ in $\left.\mathrm{ZrSi}_{2}\right)$.

Simulated site-site distance pair correlation functions g(r) of two models $\mathrm{Zr}_{39} \mathrm{Si}_{3} \mathrm{~B}_{30} \mathrm{C}_{8} \mathrm{~N}_{20}$ (pathway (1) at $3 \mathrm{~mol} \% \mathrm{Si}_{3} \mathrm{~N}_{4}$ ) and $\mathrm{Zr}_{25} \mathrm{Si}_{18} \mathrm{~B}_{16} \mathrm{C}_{8} \mathrm{~N}_{33}$ (pathway (2)at 19 mol\% $\mathrm{Si}_{3} \mathrm{~N}_{4}$ )shown in Figure 5 support our observations. In particular, partial g(r)'s show that both systems exhibit no C-C, C-N, or N-N bonding. Zr $\cdots \mathrm{Zr}$ correlations at 3.2-3.3 Åare comparable to distances between $\mathrm{Zr}$ layers in hexagonal $\mathrm{ZrB}_{2}(3.17 \AA$ ), c-ZrN (3.27 $\AA$ ) and c-ZrC (3.30 $\AA)$.

We can characterize- qualitatively - thestructural order that occurs in these $\mathrm{Zr}-\mathrm{Si}$-BC-N models. Zr tends to arrange in layers, each layer resembling closest packing (сp) in a plane. Interstitials spaces between the layers are filled with N, C and B in such a way thatZr is, ideally, six-fold coordinated. These Zr-centered octahedra fuse together andform small nuclei of $\mathrm{ZrN}(\mathrm{C})$ (Figure 6,left). B atomstend to aggregatein B-B networks forming rings like in the honeycomb B-substructure of $\mathrm{ZrB}_{2}$, with $\mathrm{Zr}$ located above and below the rings(Figure 6, right).The $\mathrm{ZrB}_{2}$ nuclei do not appear as frequent as $\mathrm{ZrN}(\mathrm{C}$ ) nuclei. These fragments and nuclei appear in melt-quench models and annealed models alike, with more pronounced order in the latter.

The impact of increasing $\mathrm{Si}_{3} \mathrm{~N}_{4}$ content is a decreasing tendency to form nuclei of any kind. For example, models with two and more units of $\mathrm{Si}_{3} \mathrm{~N}_{4}$ are free of $\mathrm{B}_{6}$-rings. Moreover, the number of $\mathrm{Zr}$-centered octahedra fused together (size of $\mathrm{ZrN}(\mathrm{C})$ nuclei) decreases significantly as the $\mathrm{Si}_{3} \mathrm{~N}_{4}$ content increases. Overall, structures containing $\mathrm{Si}_{3} \mathrm{~N}_{4}$ are less ordered and exhibit a larger variety of local environments for all atoms.

\section{c) Thermochemistry:}

In Table 1 we show the computed enthalpy of formation of $\mathrm{ZrSiBCN}$ models. For each composition we only consider the model with the lowest energy. The enthalpy of 
formation is defined with reference to the crystal structures $\mathrm{ZrN}, \mathrm{ZrC}, \mathrm{ZrB} 2$, and $\beta-\mathrm{Si}_{3} \mathrm{~N}_{4}$, according to:

$$
\Delta \mathrm{H}_{\mathrm{f}}=\mathrm{E}(\mathrm{a}-\mathrm{ZrSiBCN})-\left[\mathrm{m} \cdot \mathrm{E}\left(\mathrm{c}-\mathrm{ZrB}_{2}\right)+\mathrm{n} \cdot \mathrm{E}(\mathrm{c}-\mathrm{ZrN})+\mathrm{p} \cdot \mathrm{E}(\mathrm{c}-\mathrm{ZrC})+\mathrm{r} \cdot \mathrm{E}\left(\beta-\mathrm{Si}_{3} \mathrm{~N}_{4}\right) / \mathrm{n}_{\text {atoms }}\right.
$$

where m,n,p and $\mathrm{r}$ stand for formula units(f.u.) of c-ZrB 2 , c-ZrN, c-ZrC and $\beta-\mathrm{Si}_{3} \mathrm{~N}_{4}$ respectively. Reference energies for the crystalline structures are:

c- $-\mathrm{ZrB}_{2}=-24.74$ eV/f.u.; c-ZrC = -19.33 eV/f.u.; c-ZrN = -20.23 eV/f.u.; $\beta-\mathrm{Si}_{3} \mathrm{~N}_{4}=-58.69$ eV/f.u.

Overall, $\Delta \mathrm{H}_{\mathrm{f}}$ of these models is about $0.4-0.5 \mathrm{eV} /$ atom with the exception of the parent model, $\mathrm{Zr}_{42} \mathrm{~B}_{32} \mathrm{C}_{8} \mathrm{~N}_{18}$, for which the enthalpy of formation is only half as high, 0.24 eV/atom.For amorphous $\mathrm{Si}_{3} \mathrm{~N}_{4}$ itself, we find consistently a value of $0.2-0.3 \mathrm{eV} /$ atom for the enthalpy of formation, which parallels earlier investigations.[46]Hence, the addition of $\mathrm{Si}_{3} \mathrm{~N}_{4}$ to a phase assemblage of $\mathrm{ZrB}_{2}, \mathrm{ZrC}$, and $\mathrm{ZrN}$ significantly increases $\Delta \mathrm{H}_{\mathrm{f}}$. This increase of $\Delta \mathrm{H}_{\mathrm{f}}$ parallels the observed decrease to form ordered nuclei with addition of $\mathrm{Si}_{3} \mathrm{~N}_{4}$.

\begin{tabular}{|c|c|c|c|c|c|c|c|}
\hline \multirow{2}{*}{ Pathway } & Composition & $\begin{array}{c}\text { Energy } \\
(\mathrm{eV} / \mathrm{atom})\end{array}$ & $\mathrm{m}$ & $\mathrm{n}$ & $\mathrm{p}$ & $\mathrm{r}$ & $\begin{array}{c}\Delta \mathrm{H}_{\mathrm{f}} \\
(\mathrm{eV} / \mathrm{atom})\end{array}$ \\
\hline \multirow{2}{*}{ Parent } & $\mathrm{Zr}_{42} \mathrm{~B}_{32} \mathrm{C}_{8} \mathrm{~N}_{18}$ & -9.81 & 16 & 18 & 8 & 0 & 0.24 \\
\hline \multirow{3}{*}{ Pathway (1) } & $\mathrm{Zr}_{39} \mathrm{Si}_{3} \mathrm{~B}_{30} \mathrm{C}_{8} \mathrm{~N}_{20}$ & -8.67 & 15 & 16 & 8 & 1 & 0.41 \\
\cline { 2 - 9 } & $\mathrm{Zr}_{36} \mathrm{Si}_{6} \mathrm{~B}_{28} \mathrm{C}_{8} \mathrm{~N}_{22}$ & -8.57 & 14 & 14 & 8 & 2 & 0.45 \\
\cline { 2 - 9 } & $\mathrm{Zr}_{33} \mathrm{Si}_{9} \mathrm{~B}_{26} \mathrm{C}_{8} \mathrm{~N}_{24}$ & -8.49 & 13 & 12 & 8 & 3 & 0.46 \\
\cline { 2 - 9 } & $\mathrm{Zr}_{30} \mathrm{Si}_{12} \mathrm{~B}_{24} \mathrm{C}_{8} \mathrm{~N}_{26}$ & -8.40 & 12 & 10 & 8 & 4 & 0.48 \\
\hline
\end{tabular}




\begin{tabular}{|l|l|l|l|l|l|l|c|}
\hline & $\mathrm{Zr}_{27} \mathrm{Si}_{15} \mathrm{~B}_{22} \mathrm{C}_{8} \mathrm{~N}_{28}$ & -8.31 & 11 & 8 & 8 & 5 & 0.51 \\
\hline \multirow{3}{*}{ Pathway (2) } & $\mathrm{Zr}_{25} \mathrm{Si}_{18} \mathrm{~B}_{16} \mathrm{C}_{8} \mathrm{~N}_{33}$ & -8.35 & 8 & 9 & 8 & 6 & 0.52 \\
\hline \multirow{3}{*}{ Pathway (3) } & $\mathrm{Zr}_{37} \mathrm{Si}_{6} \mathrm{~B}_{24} \mathrm{C}_{8} \mathrm{~N}_{25}$ & -8.68 & 12 & 17 & 8 & 2 & 0.45 \\
\cline { 2 - 9 } & $\mathrm{Zr}_{32} \mathrm{Si}_{12} \mathrm{~B}_{16} \mathrm{C}_{8} \mathrm{~N}_{32}$ & -8.63 & 8 & 16 & 8 & 4 & 0.48 \\
\cline { 2 - 8 } & $\mathrm{Zr}_{27} \mathrm{Si}_{18} \mathrm{~B}_{8} \mathrm{C}_{8} \mathrm{~N}_{39}$ & -8.64 & 4 & 15 & 8 & 6 & 0.45 \\
\hline \multirow{3}{*}{ Pathway (4) } & $\mathrm{Zr}_{40} \mathrm{Si}_{3} \mathrm{~B}_{26} \mathrm{C}_{8} \mathrm{~N}_{23}$ & -8.77 & 13 & 19 & 8 & 1 & 0.43 \\
\cline { 2 - 9 } & $\mathrm{Zr}_{38} \mathrm{Si}_{6} \mathrm{~B}_{20} \mathrm{C}_{8} \mathrm{~N}_{28}$ & -8.86 & 10 & 20 & 8 & 2 & 0.38 \\
\cline { 2 - 9 } & $\mathrm{Zr}_{36} \mathrm{Si}_{9} \mathrm{~B}_{14} \mathrm{C}_{8} \mathrm{~N}_{33}$ & -8.87 & 7 & 21 & 8 & 3 & 0.42 \\
\cline { 2 - 9 } & $\mathrm{Zr}_{34} \mathrm{Si}_{12} \mathrm{~B}_{8} \mathrm{C}_{8} \mathrm{~N}_{38}$ & -8.91 & 4 & 22 & 8 & 4 & 0.43 \\
\hline
\end{tabular}

Table 1: Enthalpy of formation $\left(\Delta \mathrm{H}_{\mathrm{f}}\right)$ of a-ZrSiBCN with respect to crystalline phases $\left(\mathrm{ZrB}_{2}, \mathrm{ZrN}, \mathrm{ZrC}\right.$ and $\left.\beta-\mathrm{Si}_{3} \mathrm{~N}_{4}\right)$. For each composition only the model with lowest energy was considered.Columns $\mathrm{m}, \mathrm{n}, \mathrm{p}$, and $\mathrm{r}$ show formula units (f.u.) of c- $\mathrm{ZrB}_{2}, \mathrm{c}-\mathrm{ZrN}$, c-ZrC and $\beta-\mathrm{Si}_{3} \mathrm{~N}_{4}$, respectively.

\section{d)Elastic Moduli and Vickers hardness:}

Elastic constantsc $c_{\mathrm{ij}}$ (there are 21 independent elements of $\mathrm{c}_{\mathrm{ij}}$ for each model, since the structures do not possess any symmetry) are computed for all ZrSiBCNmodels, six for each composition. The stiffness matrix $\left(\mathrm{c}_{\mathrm{ij}}\right)$ of an isotropic model comprisestwoindependent values only, since $c_{11}=c_{22}=c_{33}, c_{12}=c_{23}=c_{13}$ and $c_{44}=c_{55}=$ $\mathrm{c}_{66}=\left(\mathrm{c}_{11}-\mathrm{c}_{12}\right) / 2$. All other elements vanish.[47] This is not fulfilled for individual models we constructed, most likely because their size is not large enough to be "isotropic". 
However, averaging $\mathrm{c}_{\mathrm{ij}}$ for models of the same composition yields isotropic behavior within the margin of error. A representative average stiffness matrix, for composition $\mathrm{Zr}_{39} \mathrm{Si}_{3} \mathrm{~B}_{30} \mathrm{C}_{8} \mathrm{~N}_{20}$,is shown in Table 2:

\begin{tabular}{|c|c|c|c|c|c|c|}
\hline$c_{\mathrm{ij}}$ & 1 & 2 & 3 & 4 & 5 & 6 \\
\hline 1 & $266 \pm 14$ & $137 \pm 9$ & $118 \pm 5$ & $-20 \pm 17$ & $13 \pm 13$ & $5 \pm 6$ \\
\hline 2 & $137 \pm 9$ & $258 \pm 7$ & $114 \pm 9$ & $10 \pm 11$ & $-17 \pm 7$ & $-7 \pm 5$ \\
\hline 3 & $118 \pm 5$ & $114 \pm 9$ & $265 \pm 15$ & $-11 \pm 9$ & $12 \pm 9$ & $6 \pm 3$ \\
\hline 4 & $-20 \pm 17$ & $10 \pm 11$ & $-11 \pm 9$ & $61 \pm 16$ & $19 \pm 14$ & $4 \pm 5$ \\
\hline 5 & $13 \pm 13$ & $-17 \pm 7$ & $12 \pm 9$ & $19 \pm 14$ & $58 \pm 10$ & $0 \pm 6$ \\
\hline 6 & $5 \pm 6$ & $-7 \pm 5$ & $6 \pm 3$ & $4 \pm 5$ & $0 \pm 6$ & $82 \pm 4$ \\
\hline
\end{tabular}

Table2: Stiffness matrix [6x6] of $\mathrm{Zr}_{39} \mathrm{Si}_{3} \mathrm{~B}_{30} \mathrm{C}_{8} \mathrm{~N}_{20}$ averaged over 5 independent meltquench models. For each entry of $\mathrm{c}_{\mathrm{ij}}$ we list the value together with the standard error. The minimum and maximum standard errors are 3 and 16 GPa, respectively, with an average of $9 \mathrm{GPa}$.

Using the stiffness $\left(\mathrm{c}_{\mathrm{ij}}\right)$ and compliance $\left(\mathrm{s}_{\mathrm{ij}}\right)$ matrices, we compute the elastic moduli $\mathrm{B}, \mathrm{G}$ and E using the Voigt, Reuss and Hill (V-R-H) approach.[42-44] Voigt's method yieldsan upper boundary for an elastic modulus: bulk modulus $B_{V}=(1 / 9)\left[\left(c_{11}+c_{22}+c_{33}\right)+\right.$ $\left.2\left(\mathrm{c}_{12}+\mathrm{c}_{13}+\mathrm{c}_{23}\right)\right]$ and shear modulus $\mathrm{G}_{\mathrm{V}}=(1 / 15)\left[\left(\mathrm{c}_{11}+\mathrm{c}_{22}+\mathrm{c}_{33}\right)-\left(\mathrm{c}_{12}+\mathrm{c}_{13}+\mathrm{c}_{23}\right)+\right.$ $3\left(c_{44}+c_{55}+c_{66}\right)$. Reuss's method provides a lower bound of an elastic modulus: $B_{R}$ $=\left[\left(\mathrm{s}_{11}+\mathrm{s}_{22}+\mathrm{s}_{33}\right)+2\left(\mathrm{~s}_{12}+\mathrm{s}_{13}+\mathrm{s}_{23}\right)\right]^{-1}$ and $\mathrm{G}_{\mathrm{R}}=15\left[4\left(\mathrm{~s}_{11}+\mathrm{s}_{22}+\mathrm{s}_{33}\right)-\left(\mathrm{s}_{12}+\mathrm{s}_{13}+\mathrm{s}_{23}\right)+\right.$ $\left.3\left(\mathrm{~s}_{44}+\mathrm{s}_{55}+\mathrm{s}_{66}\right)\right]^{-1}$. The Hill method gives an average of the upper and lower bounds as $\mathrm{B}_{\mathrm{H}}$ $=(1 / 2)\left(B_{V}+B_{R}\right)$ and $G_{H}=(1 / 2)\left(G_{V}+G_{R}\right)$. The Young's modulus $(E)$ is related to the bulk 
(B) and shear $(\mathrm{G})$ moduli as $E=9 B G /(3 B+G)$, and our estimate of $E$ is based on the aggregate Hill values of B and G.For a given compositionthe moduli can be determinedeither byfirst averaging the $\mathrm{c}_{\mathrm{ij}}$ and computing modulifrom the averaged stiffness matrix or alternatively by first computing moduli for each model and then averaging the moduli for each composition. We choose the latter approach, since it provides us a simple error estimate of each modulus based on its average and its variation (in comparison to the requirement to do a full error propagation from stiffness coefficients).Vickers hardness $\left(\mathrm{H}_{\mathrm{V}}\right)$ is estimated using the empirical relation between hardness and elastic moduli as proposed by Chen: $H_{V}=2\left(G^{3} / B^{2}\right)^{0.585}-3$.[45]

In Table 3, we summarize results of elastic moduli and hardness $\left(\mathrm{H}_{\mathrm{V}}\right)$ for crystalline structures, the parent composition $\mathrm{Zr}_{42} \mathrm{~B}_{32} \mathrm{C}_{8} \mathrm{~N}_{18}$ and for $\mathrm{ZrSiBCN}$ models. There is reasonable agreement between our computed data with references in literature. For example, experimental data for the independent elastic constants of hexagonal $\mathrm{ZrB}_{2}$ (space group: P6/mmm) are $\mathrm{c}_{11}=581 \mathrm{GPa}, \mathrm{c}_{12}=55 \mathrm{GPa}, \mathrm{c}_{13}=121 \mathrm{GPa}, \mathrm{c}_{33}=445 \mathrm{GPa}$, and $\mathrm{c}_{44}=240 \mathrm{GPa}$.[48]This yields B, G, E of $244 \mathrm{GPa}, 233 \mathrm{GPa}$, and $530 \mathrm{GPa}$, respectively, within the V-R-H approximation. Our computed moduli for $\mathrm{ZrB}_{2}$ are 247 GPa, 214 GPa, and 499 GPa, for B, G, and E, respectively, with a deviation of less than 10\% from the experimental data. For crystalline ZrC, we compute moduli B and G to 236 GPa and $146 \mathrm{GPa}$, respectively, which provides an estimate of $18 \mathrm{GPa}$ forH $_{\mathrm{V}}$. Thisis in close agreement with recent computational data $(\mathrm{B}=234 \mathrm{GPa}, \mathrm{G}=164 \mathrm{GPa}, \mathrm{Hv}=23$ GPa, [49]), and differences arise only from the use of different pseudopotentials and cutoffs $\left(\mathrm{E}_{\text {cut-off }}=350 \mathrm{eV}\right.$ against $560 \mathrm{eV}$ inreference[49]. Experimental values ofBfor ZrC, which depend on the measurement technique and sample microstructure, range between 207 and 223 GPa. [50], [51]Our computed elastic moduli of $\mathrm{ZrN}$ are B = $268 \mathrm{GPa}, \mathrm{G}=$ $195 \mathrm{GPa}$, and E= $470 \mathrm{GPa}$,somewhat larger than recent computational data(B = $245 \mathrm{GPa}$, $\mathrm{G}=150 \mathrm{GPa}, \mathrm{E}=375 \mathrm{GPa}$ )[52].From nano-indentation measurements, the elastic constantsfor $\beta-\mathrm{Si}_{3} \mathrm{~N}_{4}$ are determined to be: $\mathrm{c}_{11}=343 \mathrm{GPa}, \mathrm{c}_{12}=136 \mathrm{GPa}, \mathrm{c}_{13}=120 \mathrm{GPa}, \mathrm{c}_{33}=$ 
600 GPaand $\mathrm{c}_{44}=124 \mathrm{GPa}$. [53] Accordingly, the elastic moduli from V-R-H approximations are $\mathrm{B}=227 \mathrm{GPa}, \mathrm{G}=120 \mathrm{GPa}, \mathrm{E}=307 \mathrm{GPa}$ and $\mathrm{H}_{\mathrm{V}}=13 \mathrm{GPa}$. Computational data in reference [54] for $\beta-\mathrm{Si}_{3} \mathrm{~N}_{4}$ yieldsvalues of $\mathrm{B}=225 \mathrm{GPa}$ and $\mathrm{G}=$ 120 GPa. [54]Comparison of these values with our computed valueslisted in Table 3 for $\beta-\mathrm{Si}_{3} \mathrm{~N}_{4}(\mathrm{~B}=236 \mathrm{GPa}, \mathrm{G}=126 \mathrm{GPa}, \mathrm{E}=313 \mathrm{GPa})$ shows good agreement. [54]For the parent compositiona- $\mathrm{Zr}_{42} \mathrm{~B}_{32} \mathrm{C}_{8} \mathrm{~N}_{18}$, we compute $\mathrm{B}, \mathrm{G}, \mathrm{E}$, and $\mathrm{H}_{\mathrm{V}}$ of 171,79 , 206,and 8 GPa, respectively.

In Figure 7 we plotbulk modulus B, shear modulus G,Young's modulus E and Vickers hardness $\mathrm{H}_{\mathrm{V}}$ as a function of $\mathrm{Si}_{3} \mathrm{~N}_{4}$ content (mol-\% of $\mathrm{Si}_{3} \mathrm{~N}_{4}$ ) along the selected pathways of the composition diagram (see Fig. 3).

Linear fits to the data in Figure 7 show a decrease of elastic moduli and hardness with increasing $\mathrm{Si}_{3} \mathrm{~N}_{4}$-content. For instance, addition of 1 mol-\% of $\mathrm{Si}_{3} \mathrm{~N}_{4}$ to compositions along pathway(1), decreasesthe bulk modulus by $1.8 \mathrm{GPa}$. For pathway(3) and (4) the decrease in $\mathrm{B}$ is $1.0 \mathrm{GPa}$ and $2.0 \mathrm{GPa}$ per $\mathrm{mol}_{\%} \mathrm{Si}_{3} \mathrm{~N}_{4}$ added, respectively. For shear modulus $(\mathrm{G})$ the decrease per mol-\% $\mathrm{Si}_{3} \mathrm{~N}_{4}$ is $1.2 \mathrm{GPa}$ for pathway(1), 0.6GPa for pathway(3) and 1.5 GPa for pathway(4). The decrease in Young's modulus (E) is 3.0, 1.6 and 4.0 GPa along pathway (1), (3) and (4) respectively. However, Vickers hardness $\left(\mathrm{H}_{\mathrm{V}}\right)$ drops only slightly (by $0.2 \mathrm{GPa}$ per mol-\% $\mathrm{Si}_{3} \mathrm{~N}_{4}$ ) along each pathway, sincethe estimate by Chen strongly correlates $\mathrm{H}_{\mathrm{V}}$ to the ratio of B and G.Overall, starting from the initial composition $\mathrm{Zr}_{42} \mathrm{~B}_{32} \mathrm{C}_{8} \mathrm{~N}_{18}$, an increase of $\mathrm{Si}_{3} \mathrm{~N}_{4}$ content in the $\mathrm{ZrSiBCN}$ models results in a decrease of elastic moduli B and G and, ultimately, of Vickers hardness. A decrease in $\mathrm{G}, \mathrm{E}$, and $\mathrm{H}_{\mathrm{V}}$ (but not in B) can be expected from a simple mixture model applied to the addition of $\mathrm{Si}_{3} \mathrm{~N}_{4}$ to a phase assemblage of $\mathrm{ZrB}_{2}, \mathrm{ZrC}$, and $\mathrm{ZrN}$. However, we show in next paragraph that effect is larger than expected and that the moduli are impacted additionally by the reduced structural order (as discussed in the previous section). 
Alongpathway(1) a simple mixture model of $\mathrm{Zr}_{42} \mathrm{~B}_{32} \mathrm{C}_{8} \mathrm{~N}_{18}$ based on mole fractions of crystalline $\mathrm{ZrN}$, $\mathrm{ZrC}$ and $\mathrm{ZrB}_{2}$ and moduli of crystalline structures given in Table 3 predicts moduli of 254 GPa, 193 GPa, and 461 GPa,for B, G, and E, respectively. Computed values are 171, 79, and 208 GPa, for B, G, and E, respectively. For the model with largest $\mathrm{Si}_{3} \mathrm{~N}_{4}$ content, $\mathrm{Zr}_{27} \mathrm{Si}_{15} \mathrm{~B}_{22} \mathrm{C}_{8} \mathrm{~N}_{28}$, a mixture modelyields198,102, and 343 GPa, and the computation gives 143, 60, and $159 \mathrm{GPa}$, for B, G, and E, respectively. Thus, computed models have significantly lower moduli than expected by a mixture model. If data of amorphous a- $\mathrm{Si}_{3} \mathrm{~N}_{4}$ (either from computed models, or using reported experimental data of $\mathrm{B}=196 \mathrm{GPa}[46]$ and $\mathrm{E}=289 \mathrm{GPa}$ [55]) is used to predict the “ideal” moduli for these compositions, the discrepancy is still significant. More importantly, the deviation from an ideal mixture model increases with $\mathrm{Si}_{3} \mathrm{~N}_{4}$ contentalong all pathways. We note thatalong pathway (1),(2) and (3) addition of $\mathrm{Si}_{3} \mathrm{~N}_{4}$ happens at the expense of $\mathrm{ZrN}$, while the $\mathrm{ZrB}_{2}$ content remains almost constant. On the other hand, along pathway (4) $\mathrm{Si}_{3} \mathrm{~N}_{4}$ is added at the expense of $\mathrm{ZrB}_{2}$, and the $\mathrm{ZrN}$ content increases slightly. Along both paths we observe significant decrease of local order with increase of $\mathrm{Si}_{3} \mathrm{~N}_{4}$ content.Therefore, for these $\mathrm{ZrSiBCN}$ models a decrease of elastic moduli correlates with a decrease in structural order, which in turn goes along with an increase of $\mathrm{Si}_{3} \mathrm{~N}_{4}$ Content.

\begin{tabular}{|c|c|c|c|c|c|}
\hline & Composition & $\begin{array}{c}\text { Bulk } \\
\text { Modulus } \\
(\mathrm{GPa})\end{array}$ & $\begin{array}{c}\text { Shear } \\
\text { Modulus } \\
(\mathrm{GPa})\end{array}$ & $\begin{array}{c}\text { Young's } \\
\text { Modulus } \\
(\mathrm{GPa})\end{array}$ & $\begin{array}{c}\text { Vickers } \\
\text { Hardness } \\
(\mathrm{GPa})\end{array}$ \\
\hline \multirow{2}{*}{$\begin{array}{c}\text { Crystalline } \\
\text { phases }\end{array}$} & $\mathrm{c}-\mathrm{ZrB} 2$ & 247 & 214 & 499 & 36 \\
\cline { 2 - 6 } & $\mathrm{c}-\mathrm{ZrN}$ & 268 & 195 & 470 & 27 \\
\cline { 2 - 6 } & $\mathrm{c}-\mathrm{ZrC}$ & 236 & 146 & 364 & 18 \\
\hline
\end{tabular}




\begin{tabular}{|c|c|c|c|c|c|}
\hline & $\beta-\mathrm{Si}_{3} \mathrm{~N}_{4}$ & 236 & 126 & 313 & 13 \\
\hline Parent & $\mathrm{Zr}_{42} \mathrm{~B}_{32} \mathrm{C}_{8} \mathrm{~N}_{18}$ & $171 \pm 8$ & $79 \pm 5$ & $206 \pm 13$ & $8 \pm 4$ \\
\hline \multirow{5}{*}{$\begin{array}{l}\text { Pathway } \\
\text { (1) }\end{array}$} & $\mathrm{Zr}_{39} \mathrm{Si}_{3} \mathrm{~B}_{30} \mathrm{C}_{8} \mathrm{~N}_{20}$ & $190 \pm 22$ & $86 \pm 4$ & $225 \pm 11$ & $8 \pm 1$ \\
\hline & $\mathrm{Zr}_{36} \mathrm{Si}_{6} \mathrm{~B}_{28} \mathrm{C}_{8} \mathrm{~N}_{22}$ & $158 \pm 4$ & $67 \pm 4$ & $177 \pm 9$ & $6 \pm 1$ \\
\hline & $\mathrm{Zr}_{33} \mathrm{Si}_{9} \mathrm{~B}_{26} \mathrm{C}_{8} \mathrm{~N}_{24}$ & $153 \pm 5$ & $71 \pm 2$ & $184 \pm 5$ & $7 \pm 0$ \\
\hline & $\mathrm{Zr}_{30} \mathrm{Si}_{12} \mathrm{~B}_{24} \mathrm{C}_{8} \mathrm{~N}_{2}$ & $152 \pm 3$ & $68 \pm 1$ & $178 \pm 3$ & $6 \pm 0$ \\
\hline & $\mathrm{Zr}_{27} \mathrm{Si}_{15} \mathrm{~B}_{22} \mathrm{C}_{8} \mathrm{~N}_{2}$ & $143 \pm 3$ & $60 \pm 2$ & $159 \pm 5$ & $5 \pm 0$ \\
\hline $\begin{array}{c}\text { Pathway } \\
\text { (2) }\end{array}$ & $\mathrm{Zr}_{25} \mathrm{Si}_{18} \mathrm{~B}_{16} \mathrm{C}_{8} \mathrm{~N}_{3}$ & $144 \pm 4$ & $59 \pm 3$ & $157 \pm 8$ & $5 \pm 1$ \\
\hline \multirow{3}{*}{$\begin{array}{l}\text { Pathway } \\
\text { (3) }\end{array}$} & $\mathrm{Zr}_{37} \mathrm{Si}_{6} \mathrm{~B}_{24} \mathrm{C}_{8} \mathrm{~N}_{25}$ & $162 \pm 1$ & $73 \pm 1$ & $192 \pm 3$ & $7 \pm 0$ \\
\hline & $\mathrm{Zr}_{32} \mathrm{Si}_{12} \mathrm{~B}_{16} \mathrm{C}_{8} \mathrm{~N}_{3}$ & $157 \pm 2$ & $66 \pm 3$ & $174 \pm 7$ & $5 \pm 1$ \\
\hline & $\mathrm{Zr}_{27} \mathrm{Si}_{18} \mathrm{~B}_{8} \mathrm{C}_{8} \mathrm{~N}_{39}$ & $151 \pm 3$ & $69 \pm 1$ & $179 \pm 3$ & $6 \pm 0$ \\
\hline \multirow{4}{*}{$\begin{array}{c}\text { Pathway } \\
\text { (4) }\end{array}$} & $\mathrm{Zr}_{40} \mathrm{Si}_{3} \mathrm{~B}_{26} \mathrm{C}_{8} \mathrm{~N}_{23}$ & $168 \pm 2$ & $76 \pm 4$ & $198 \pm 9$ & $6 \pm 1$ \\
\hline & $\mathrm{Zr}_{38} \mathrm{Si}_{6} \mathrm{~B}_{20} \mathrm{C}_{8} \mathrm{~N}_{28}$ & $164 \pm 1$ & $70 \pm 2$ & $184 \pm 4$ & $6 \pm 0$ \\
\hline & $\mathrm{Zr}_{36} \mathrm{Si}_{9} \mathrm{~B}_{14} \mathrm{C}_{8} \mathrm{~N}_{33}$ & $153 \pm 8$ & $59 \pm 6$ & $156 \pm 15$ & $4 \pm 1$ \\
\hline & $\mathrm{Zr}_{34} \mathrm{Si}_{12} \mathrm{~B}_{8} \mathrm{C}_{8} \mathrm{~N}_{38}$ & $151 \pm 5$ & $67 \pm 2$ & $175 \pm 4$ & $6 \pm 0$ \\
\hline
\end{tabular}

Table 3: Computed B, G, and E and Vickers Hardness of crystalline $\mathrm{ZrB}_{2}$, ZrC, ZrN, and $\mathrm{Si}_{3} \mathrm{~N}_{4}$ and of amorphous $\mathrm{ZrSiBCNmodels.For} \mathrm{amorphous} \mathrm{models} \mathrm{the} \mathrm{error} \mathrm{given} \mathrm{refers} \mathrm{to}$ the standard error obtained from averaging moduli of individual models.

\section{Conclusion}

In this work, we model amorphous ZrSiBCN ceramics, which arecandidatesfor high temperature coating materials.Using melt-quench and simulated annealing techniques 
together with ab-initio molecular dynamic simulations, we generate mixtures of $\mathrm{ZrB}_{2}$, $\mathrm{ZrN}, \mathrm{ZrC}$ and $\mathrm{Si}_{3} \mathrm{~N}_{4}$ each model comprising 100 atoms. Starting from the parent composition $\mathrm{Zr}_{42} \mathrm{~B}_{32} \mathrm{C}_{8} \mathrm{~N}_{18}$ we followfour different pathways along which $\mathrm{Si}_{3} \mathrm{~N}_{4}$ can be included.Models we receive exhibit $\mathrm{Zr}$ layers as well $\mathrm{asZrB}_{2}$ and $\mathrm{ZrN}(\mathrm{C})$ nuclei. We observe, qualitatively, that structural order depends on the amount of $\mathrm{Si}_{3} \mathrm{~N}_{4}$ content in the system: the more $\mathrm{Si}_{3} \mathrm{~N}_{4}$ the lower the order. Thermochemical calculations yield an enthalpy of formation $\left(\Delta \mathrm{H}_{\mathrm{f}}\right)$ of $=0.4-0.5 \mathrm{eV} /$ atom for the $\mathrm{ZrSiBCN}$ models. We compute independent elastic constants and from those elastic moduli (B, G and E)within the V-R$\mathrm{H}$ approximations. Along each pathway, we observe decrease of B, G, E and $\mathrm{H}_{\mathrm{V}}$ with increasing $\mathrm{Si}_{3} \mathrm{~N}_{4}$ content. Values for B, G, E and $\mathrm{H}_{\mathrm{V}}$ are lower than expectations from a simple mixture model, indicating additional impact of reduced structural order uponSi ${ }_{3} \mathrm{~N}_{4}$ addition.

Consequently, while addition of $\mathrm{Si}_{3} \mathrm{~N}_{4}$ to amorphous $\mathrm{ZrBCN}$ coating materials may improve the materials' oxidation resistance, the computations show that $\mathrm{Si}_{3} \mathrm{~N}_{4}$ also impacts mechanic performance of the coatings. Most notably, we show that a significant effect arises via reduction in structural order. While sputtered $\mathrm{ZrBCN}$ coatings shownano-domain structurewith substantial proportion of nano-grains, we expect that addition of $\mathrm{Si}_{3} \mathrm{~N}_{4}$ impedes the formation of nuclei and nano-grains and increases disorder in the films. Thus, the engineers' choice will be a balance between desired oxidation resistance and target mechanical properties.

\section{Acknowledgements}

This work was supported by the National Science Foundation [grant number CMMI1335502]. The computational work was made possible through generous grants by the Texas Advance Computing Center in Austin, TACC, Texas, and by the High Performance Computing facilities at UTA. 


\section{References:}

[1] E. Wuchina, E. Opila, M. Opeka, W. Fahrenholtz, I. Talmy. UHTCs: ultra-high temperature ceramic materials for extreme environment applications, The Electrochemical Society Interface 16 (2007) 30.

[2] W.G. Fahrenholtz, E.J. Wuchina, W.E. Lee, Y. Zhou. Ultra-high temperature ceramics: materials for extreme environment applications, John Wiley \& Sons, 2014. [3] K. Upadhya, J.M. Yang, W.P. Hoffman. Materials for ultrahigh temperature structural applications, Am Ceram Soc Bull 76 (1997) 51-56.

[4] W.G. Fahrenholtz, G.E. Hilmas, I.G. Talmy, J.A. Zaykoski. Refractory diborides of zirconium and hafnium, J Am Ceram Soc 90 (2007) 1347-1364.

[5] K. Tanabe, H. Asano, Y. Katoh, O. Michikami. Properties of Superconducting Zrn Thin-Films Deposited by Dc Reactive Magnetron Sputtering, Jpn J Appl Phys 26 (1987) L570-L572.

[6] J.W. Sung, D.M. Goedde, G.S. Girolami, J.R. Abelson. Remote-plasma chemical vapor deposition of conformal ZrB2 films at low temperature: A promising diffusion barrier for ultralarge scale integrated electronics, J Appl Phys 91 (2002) 3904-3911.

[7] Y.G. Wang, Q.M. Liu, J.L. Liu, L.T. Zhang, L.F. Cheng. Deposition mechanism for chemical vapor deposition of zirconium carbide coatings, J Am Ceram Soc 91 (2008) 1249-1252.

[8] M. Zhang, J. Jiang, J. Vlček, P. Steidl, J. Kohout, R. Cerstvy, E.I. Meletis. Effect of Nitrogen Content on the Microstructure and Hardness of Hard Zr-B-C-N Films, Microscopy and Microanalysis 20 (2014) 1892-1893.

[9] M. Zhang, J. Jiang, J. Houska, J. Kohout, J. Vlcek, E.I. Meletis. A study of the microstructure evolution of hard Zr-B-C-N films by high-resolution transmission electron microscopy, Acta Mater. 77 (2014) 212-222.

[10] S.R. Levine, E.J. Opila, M.C. Halbig, J.D. Kiser, M. Singh, J.A. Salem.

Evaluation of ultra-high temperature ceramics foraeropropulsion use, J Eur Ceram Soc 22 (2002) 2757-2767.

[11] W.C. Tripp, H.C. Graham. Thermogravimetric Study of Oxidation of Zrb2 in Temperature Range of 800 Degrees to 1500 Degrees, J Electrochem Soc 118 (1971) 1195-\&.

[12] Berkowit.Jb. High-Temperature Oxidation .3. Zirconium and Hafnium Diborides, J Electrochem Soc 113 (1966) 908-\&.

[13] M. Singh, H. Wiedemeier. Chemical Interactions in Diboride-Reinforced OxideMatrix Composites, J Am Ceram Soc 74 (1991) 724-727.

[14] K.R. Janowski, R.D. Carnahan. Observations on Static and Dynamic Oxidation of Zirconium Carbides, Jom-J Min Met Mat S 17 (1965) 1042-\&.

[15] E.I. Golovko, R.F. Voitovich. Oxidation of Zirconium and Hafnium Nitrides in the Oxygen Medium, Zh Fiz Khim+ 56 (1982) 2063-2065.

[16] M. Caillet, H.F. Ayedi, J. Besson. Étude de la corrosion de revêtements réfractaires sur le zirconium II. Oxydation par l'oxygène de revêtements de carbonitrure de zirconium, Journal of the Less Common Metals 51 (1977) 323-331.

[17] E.J. Opila, N.S. Jacobson. Corrosion of ceramic materials, Materials Science and Technology. 
[18] F. Monteverde, A. Bellosi. Effect of the addition of silicon nitride on sintering behaviour and microstructure of zirconium diboride, Scripta Mater 46 (2002) 223-228. [19] F. Monteverde, A. Bellosi. Development and characterization of metal-diboridebased composites toughened with ultra-fine SiC particulates, Solid State Sci 7 (2005) 622-630.

[20] W.C. Tripp, H.H. Davis, H.C. Graham. Effect of an SiC Addition on Oxidation of ZrB2, Am Ceram Soc Bull 52 (1973) 612-616.

[21] H. Ping, G.L. Wang, W. Zhi. Oxidation mechanism and resistance of ZrB2-SiC composites, Corros Sci 51 (2009) 2724-2732.

[22] F. Monteverde, R. Savino. Stability of ultra-high-temperature ZrB2-SiC ceramics under simulated atmospheric re-entry conditions, J Eur Ceram Soc 27 (2007) 4797-4805.

[23] I.G. Talmy, J.A. Zaykoski, M.M. Opeka. High-temperature chemistry and oxidation of $\mathrm{ZrB}(2)$ ceramics containing $\mathrm{SiC}, \mathrm{Si}(3) \mathrm{N}(4), \mathrm{Ta}(5) \mathrm{Si}(3)$, and $\mathrm{TaSi}(2)$, J Am Ceram Soc 91 (2008) 2250-2257.

[24] W.H. Rhodes, E.V. Clougherty, D. Kalish. Research and development of refractory oxidation-resistant diborides. Part II. Volume IV. Mechanical properties. Technical report, 15 September 1967--15 May 1969. Other Information: UNCL. Orig. Receipt Date: 30-JUN-73, 1970. p.Medium: X; Size: Pages: 153.

[25] E.W. Neuman, G.E. Hilmas, W.G. Fahrenholtz. Strength of Zirconium Diboride to $2300^{\circ} \mathrm{C}$, J Am Ceram Soc 96 (2013) 47-50.

[26] E.W. Neuman, G.E. Hilmas, W.G. Fahrenholtz. Mechanical behavior of zirconium diboride-silicon carbide-boron carbide ceramics up to 2200 degrees C, J Eur Ceram Soc 35 (2015) 463-476.

[27] F. Monteverde, S. Guicciardi, A. Bellosi. Advances in microstructure and mechanical properties of zirconium diboride based ceramics, Mat Sci Eng a-Struct 346 (2003) 310-319.

[28] A.L. Chamberlain, W.G. Fahrenholtz, G.E. Hilmas, D.T. Ellerby. High-strength zirconium diboride-based ceramics, J Am Ceram Soc 87 (2004) 1170-1172.

[29] J. Watts, G. Hilmas, W.G. Fahrenholtz. Mechanical Characterization of ZrB2-SiC Composites with Varying SiC Particle Sizes, J Am Ceram Soc 94 (2011) 4410-4418.

[30] J. Houska, J. Kohout, J. Vlcek. Effect of $\mathrm{N}$ and Zr content on structure, electronic structure and properties of ZrBCN materials: An ab-initio study, Thin Solid Films 542 (2013) 225-231.

[31] J. Houska, P. Mares, V. Simova, S. Zuzjakova, R. Cerstvy, J. Vlcek. Dependence of characteristics of MSiBCN (M = Ti, Zr, Hf) on the choice of metal element:

Experimental and ab-initio study, Thin Solid Films 616 (2016) 359-365.

[32] P. Hohenberg, W. Kohn. Inhomogeneous Electron Gas, Physical Review 136 (1964) B864-B871.

[33] G. Kresse, J. Hafner. Itextit $\{\mathrm{Ab}$ initio $\}$ molecular dynamics for liquid metals, Physical Review B 47 (1993) 558-561.

[34] G. Kresse, J. Hafner. Itextit $\{$ Ab initio\} molecular-dynamics simulation of the liquid-metal \char21 \{\} amorphous-semiconductor transition in germanium, Physical Review B 49 (1994) 14251-14269.

[35] G. Kresse, J. Furthmüller. Efficient iterative schemes for \textit\{ab initio\} totalenergy calculations using a plane-wave basis set, Physical Review B 54 (1996) 1116911186. 
[36] G. Kresse, J. Furthmüller. Efficiency of ab-initio total energy calculations for metals and semiconductors using a plane-wave basis set, Computational Materials Science 6 (1996) 15-50.

[37] J.P. Perdew, K. Burke, M. Ernzerhof. Generalized Gradient Approximation Made Simple, Physical Review Letters 77 (1996) 3865-3868.

[38] J.P. Perdew, K. Burke, M. Ernzerhof. Generalized Gradient Approximation Made Simple [Phys. Rev. Lett. 77, 3865 (1996)], Physical Review Letters 78 (1997) 13961396.

[39] P.E. Blöchl. Projector augmented-wave method, Physical Review B 50 (1994) 17953-17979.

[40] G. Kresse, D. Joubert. From ultrasoft pseudopotentials to the projector augmented-wave method, Physical Review B 59 (1999) 1758-1775.

[41] Y. Le Page, P. Saxe. Symmetry-general least-squares extraction of elastic data for strained materials from ab initio calculations of stress, Physical Review B 65 (2002).

[42] W. Voigt. Lehrbuch der Kristallphysik, B. B. Teubner, Leipzig, 1928.

[43] A. Reuss. Berechnung der Fließgrenze von Mischkristallen auf Grund der Plastizitätsbedingung für Einkristalle, ZAMM - Journal of Applied Mathematics and Mechanics / Zeitschrift für Angewandte Mathematik und Mechanik 9 (1929) 49-58.

[44] R. Hill. The Elastic Behaviour of a Crystalline Aggregate, Proceedings of the Physical Society. Section A 65 (1952) 349.

[45] X.Q. Chen, H.Y. Niu, D.Z. Li, Y.Y. Li. Modeling hardness of polycrystalline materials and bulk metallic glasses, Intermetallics 19 (2011) 1275-1281.

[46] P. Kroll. Modelling polymer-derived ceramics, J Eur Ceram Soc 25 (2005) 163174.

[47] J.F. Nye. Physical Properties of Crystals Oxford Univ. Press, New York, 1957.

[48] N.L. Okamoto, M. Kusakari, K. Tanaka, H. Inui, M. Yamaguchi, S. Otani.

Temperature dependence of thermal expansion and elastic constants of single crystals of ZrB2 and the suitability of ZrB2 as a substrate for GaN film, J Appl Phys 93 (2003) 8893.

[49] C.W. Xie, A.R. Oganov, D. Li, T.T. Debela, N. Liu, D. Dong, Q.F. Zeng. Effects of carbon vacancies on the structures, mechanical properties, and chemical bonding of zirconium carbides: a first-principles study, Phys Chem Chem Phys 18 (2016) 1229912306.

[50] H. O.Pierson. Handbook of Refractory Carbides \& Nitrides: Properties, Characteristics, Processing and Apps., Noyes Publication, 1996.

[51] R. Chang, L.J. Graham. Low-Temperature Elastic Properties of Zrc and Tic, J Appl Phys 37 (1966) 3778-\&.

[52] V.I. Ivashchenko, P.E.A. Turchi, V.I. Shevchenko. First-principles study of elastic and stability properties of $\mathrm{ZrC}-\mathrm{ZrN}$ and $\mathrm{ZrC}-\mathrm{TiC}$ alloys, J Phys-Condens Mat 21 (2009).

[53] J.C. Hay, E.Y. Sun, G.M. Pharr, P.F. Becher, K.B. Alexander. Elastic Anisotropy of ß-Silicon Nitride Whiskers, J Am Ceram Soc 81 (1998) 2661-2669.

[54] S. Ogata, N. Hirosaki, C. Kocer, Y. Shibutani. A comparative ab initio study of the 'ideal' strength of single crystal alpha- and beta-Si3N4, Acta Mater. 52 (2004) 233238. 
[55] A. Khan, J. Philip, P. Hess. Young's modulus of silicon nitride used in scanning force microscope cantilevers, J Appl Phys 95 (2004) 1667-1672. 

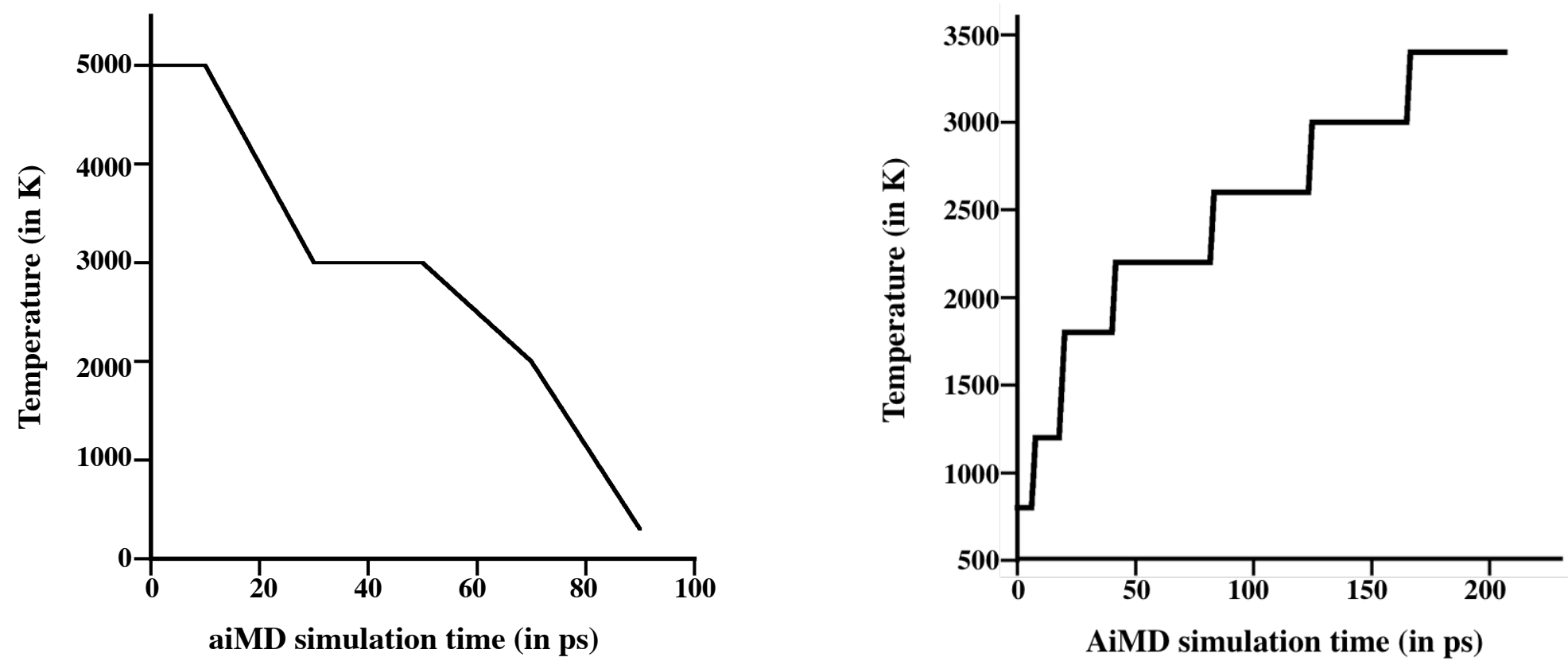


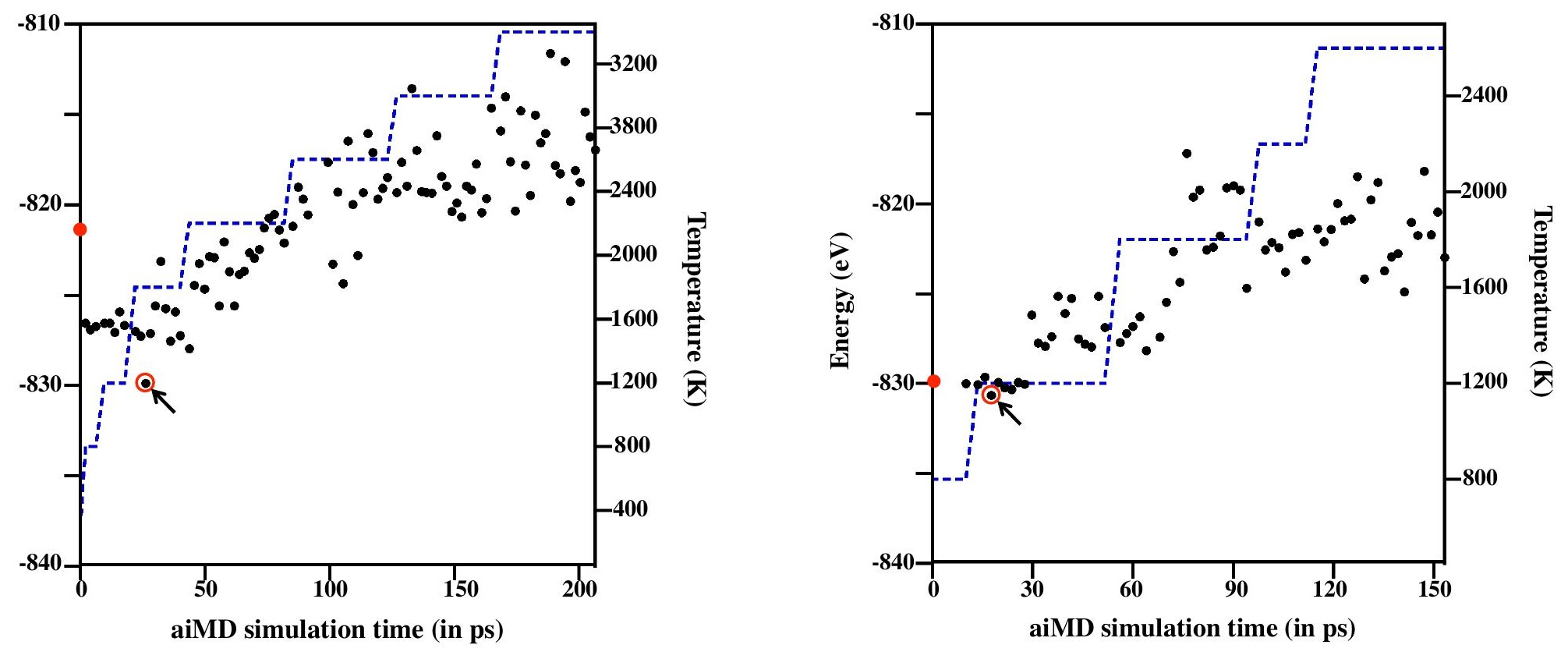


$\mathrm{Si}_{3} \mathbf{N}_{4}$

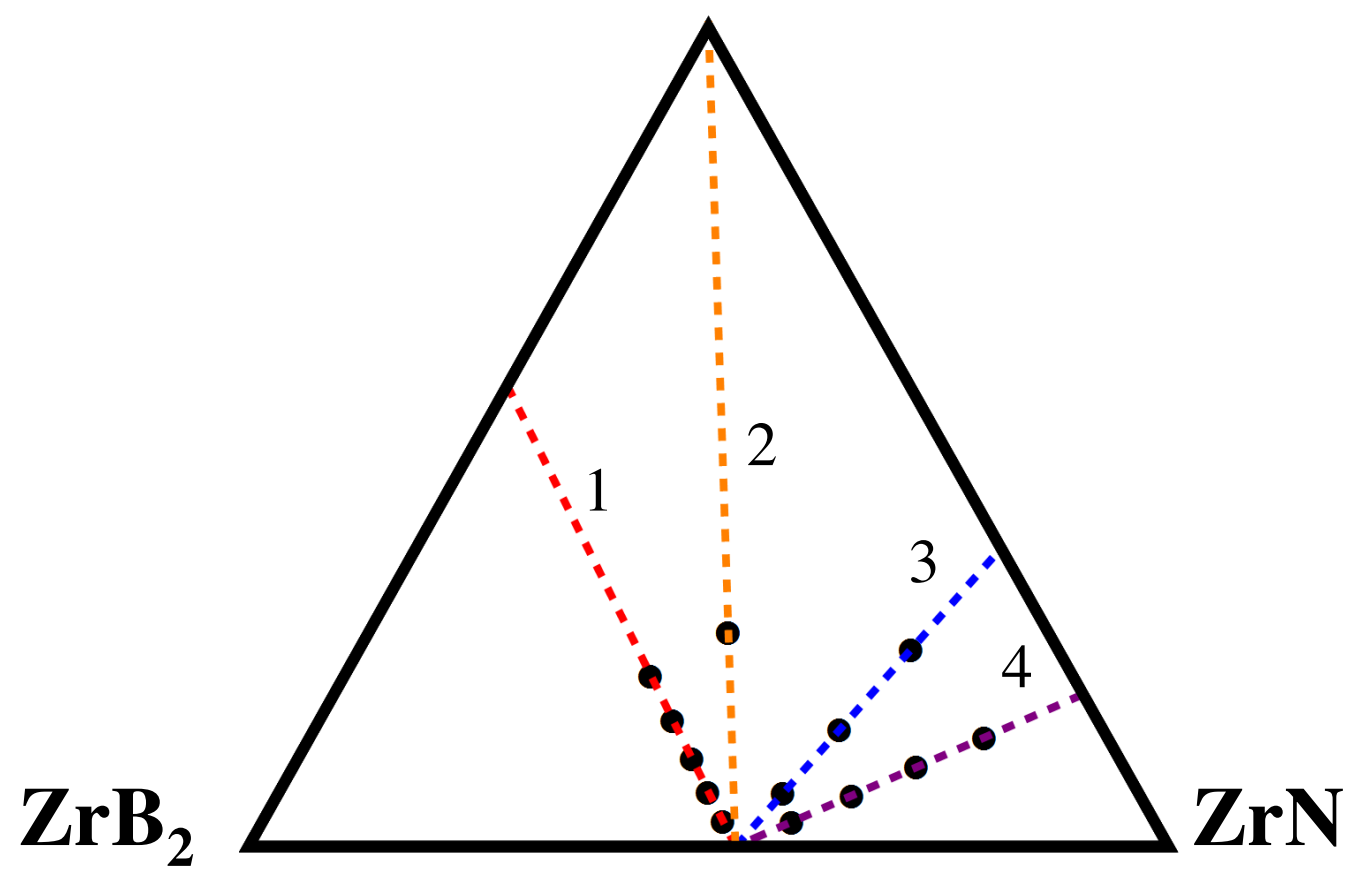




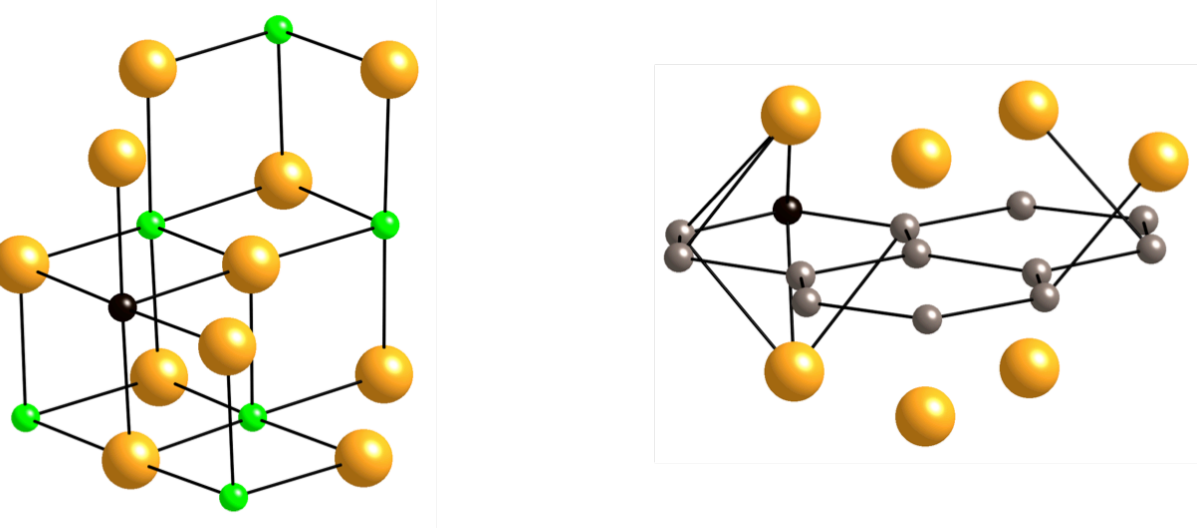


Pathway (1)

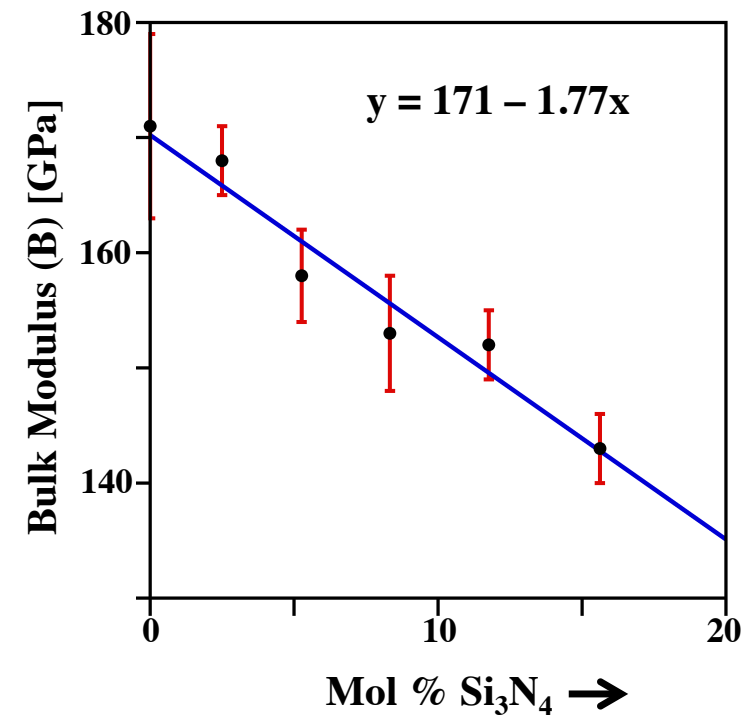

Pathway (1)

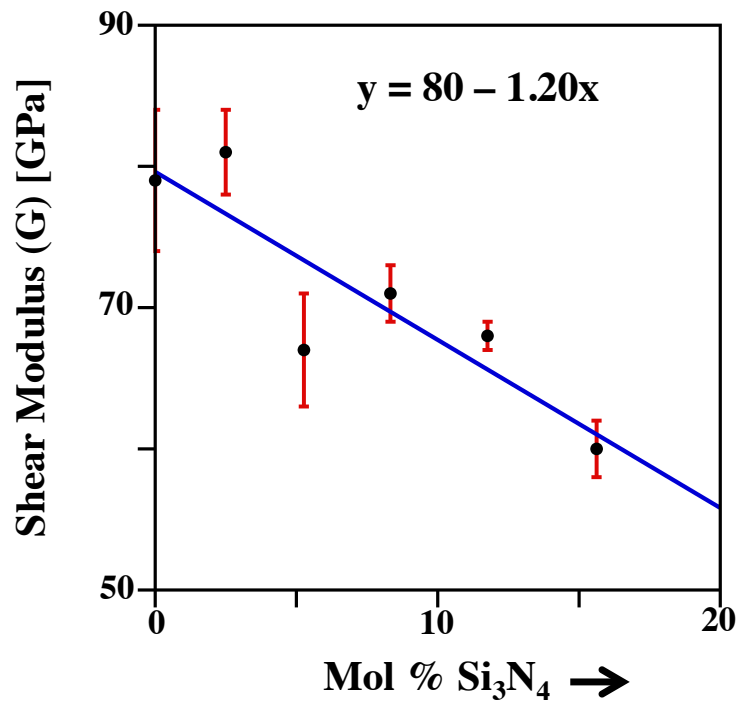

Pathway (1)

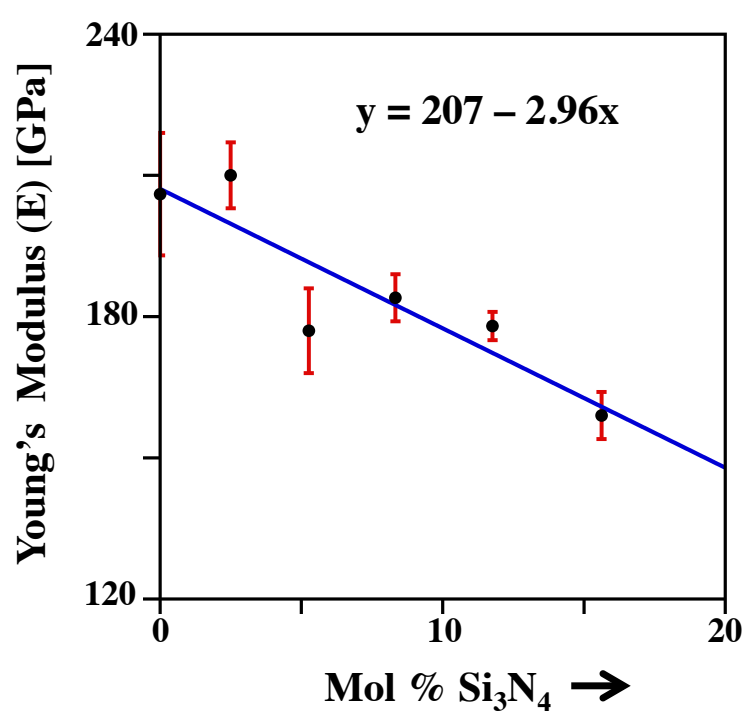

Pathway (1)

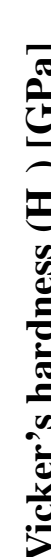

בే

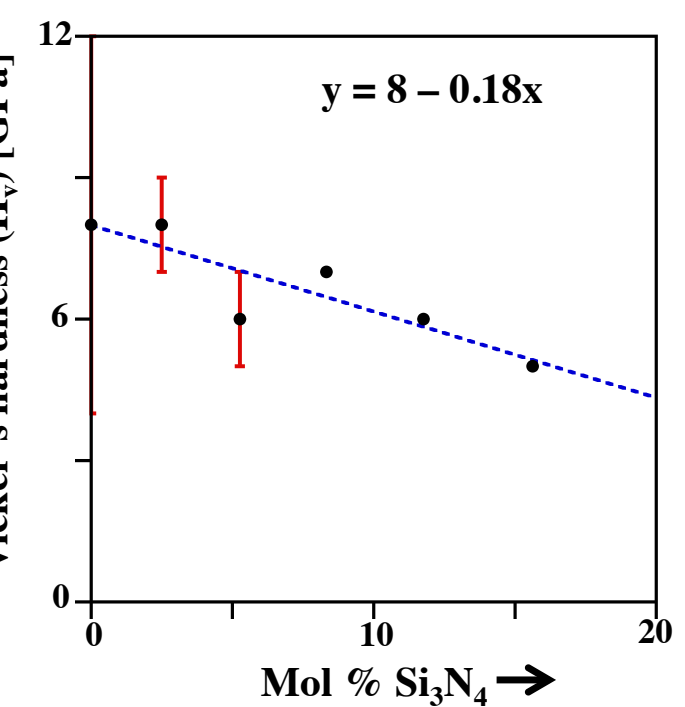

Pathway (3)

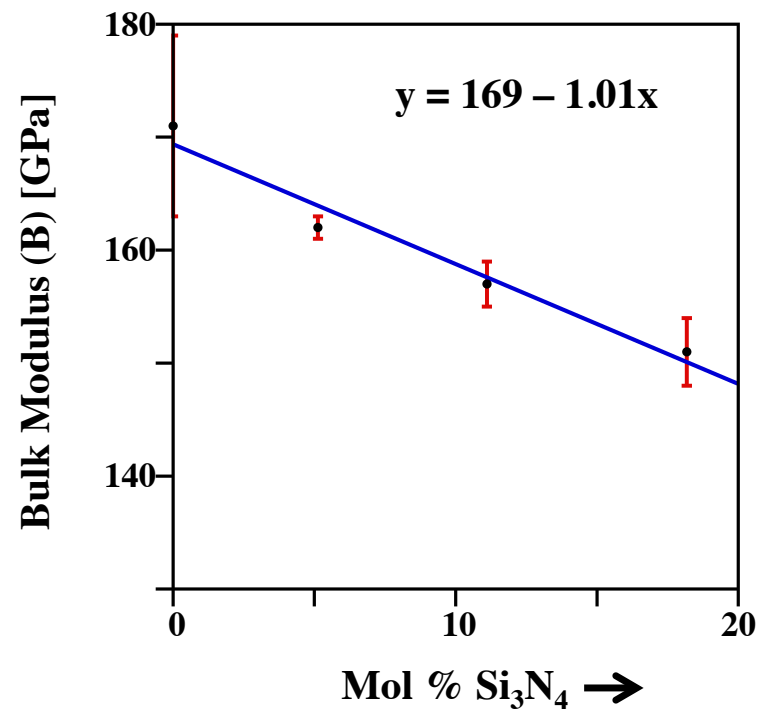

Pathway (3)

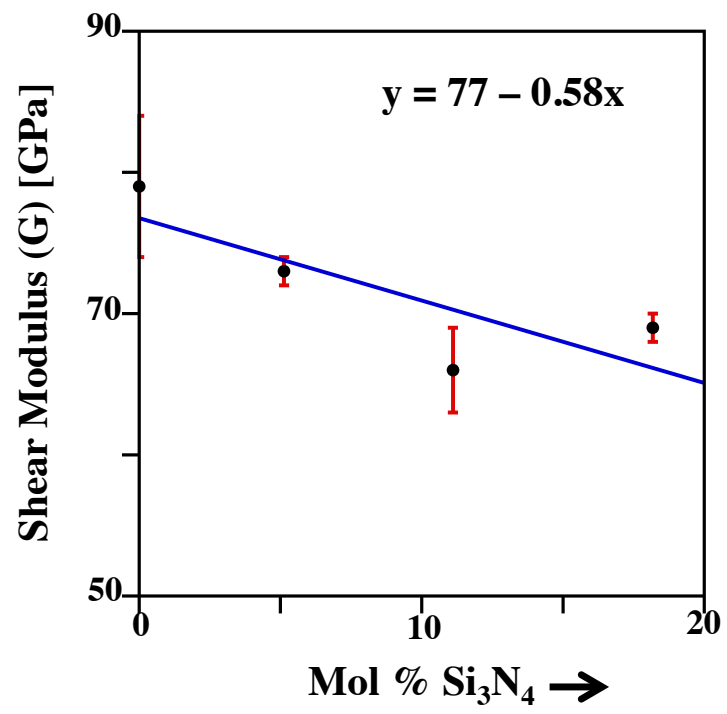

Pathway (3)

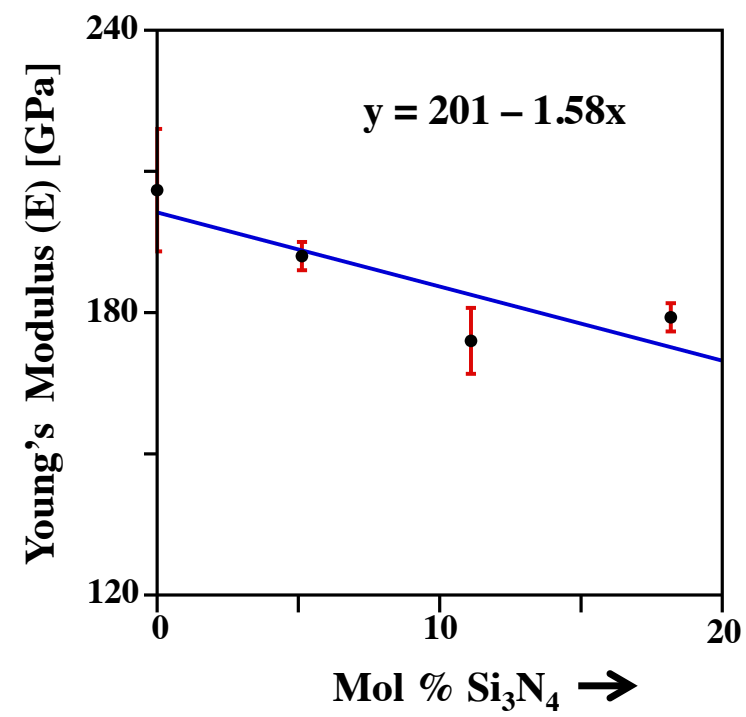

Pathway (3)

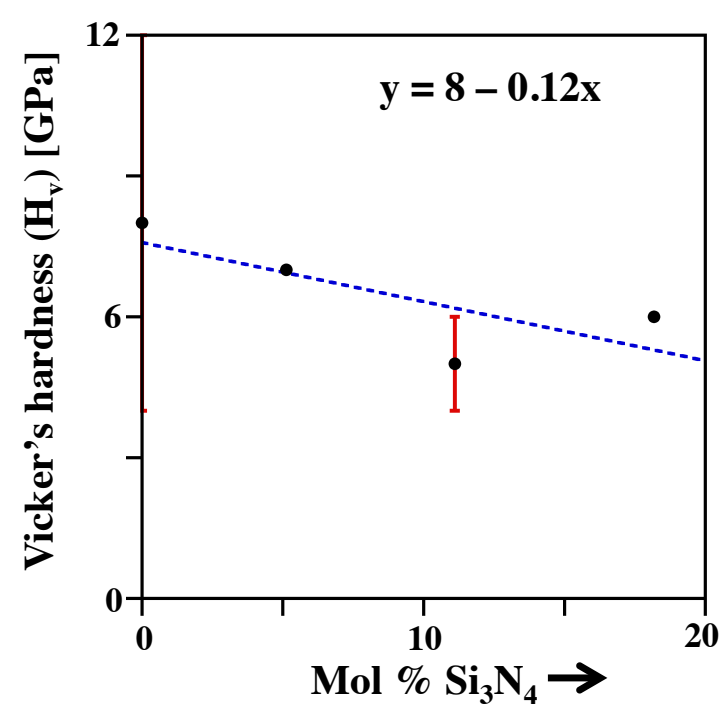

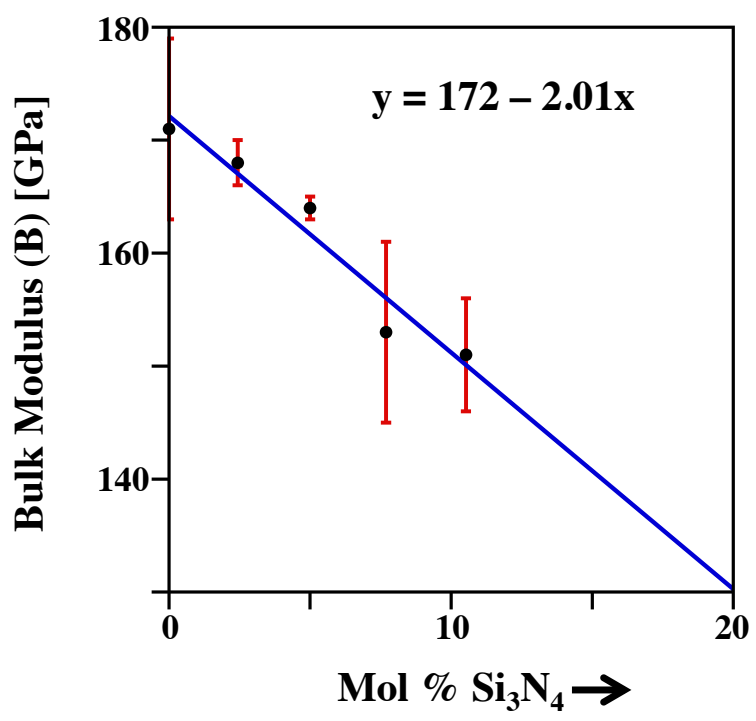

Pathway (4)

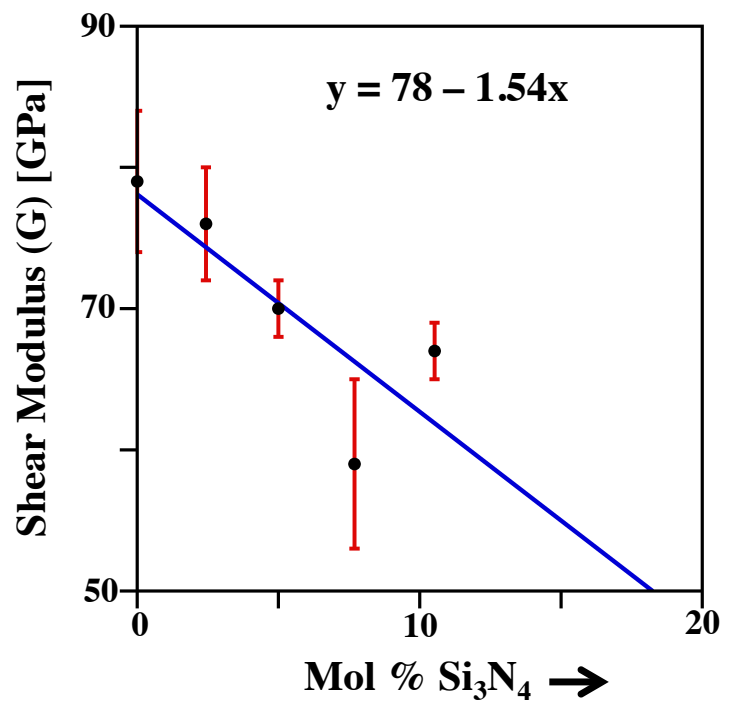

Pathway (4)

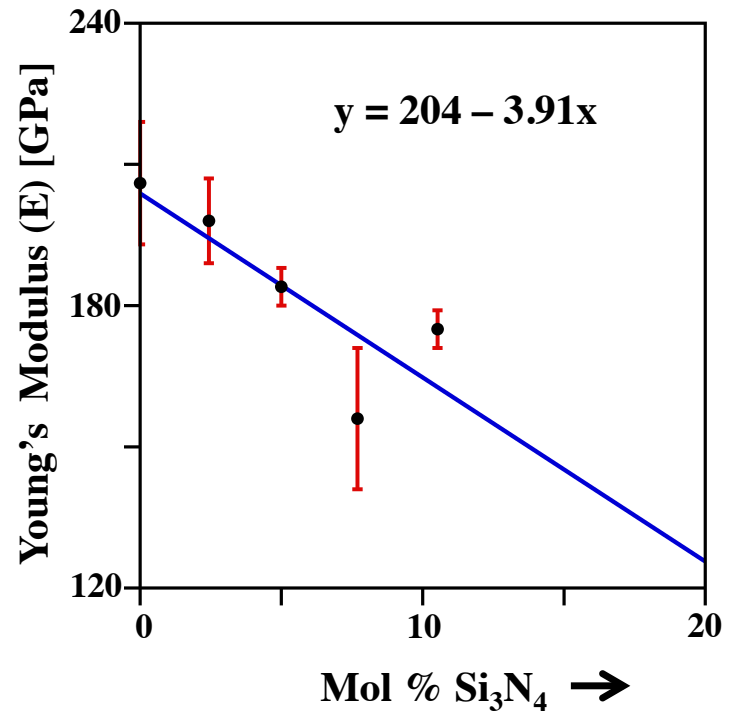

Pathway (4)

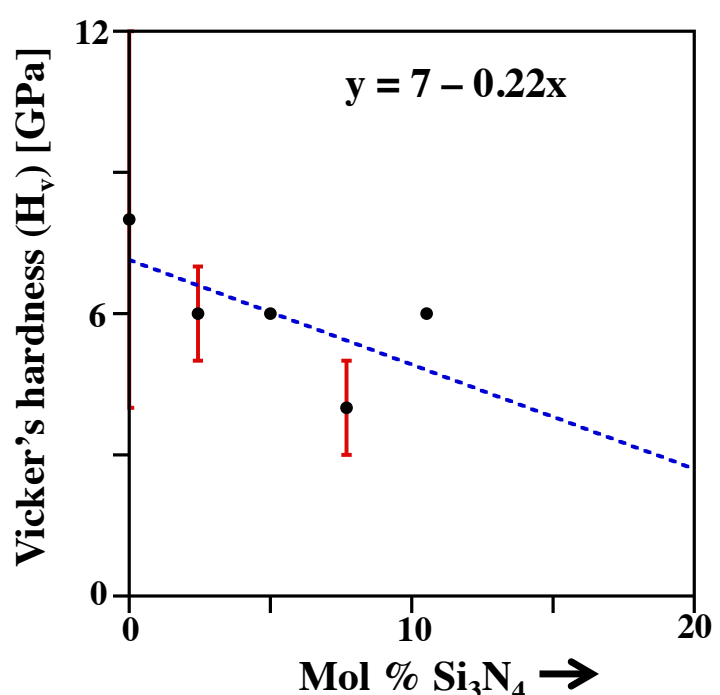

